\title{
Configurações
}

Revista de sociologia

\section{O riso: de elemento festivo a instrumento de gestão?}

Laughing: from feast element to management instrument

Rire : d'élément festive a instrument de gestion

\section{José Nuno Matos}

\section{OpenEdition}

\section{Journals}

\section{Edição electrónica}

URL: http://journals.openedition.org/configuracoes/119

DOI: 10.4000/configuracoes.119

ISSN: 2182-7419

\section{Editora}

Centro de Investigação em Ciências Sociais

\section{Edição impressa}

Data de publição: 30 Junho 2010

Paginação: 31-46

ISSN: 1646-5075

\section{Refêrencia eletrónica}

José Nuno Matos, «O riso: de elemento festivo a instrumento de gestão? », Configurações [Online],

7 | 2010, posto online no dia 18 fevereiro 2012, consultado o 01 maio 2019. URL : http://

journals.openedition.org/configuracoes/119; DOI : 10.4000/configuracoes.119

Este documento foi criado de forma automática no dia 1 Maio 2019

(c) CICS 


\title{
O riso: de elemento festivo a instrumento de gestão?
}

\author{
Laughing: from feast element to management instrument \\ Rire : d'élément festive a instrument de gestion
}

José Nuno Matos

Introdução

1 O riso tem merecido ao longo da história as mais variadas considerações e reflexões, muitas vezes antagónicas entre si. Se, em Bergson, é encarado como uma resposta automática sobre aquilo que transgride a ordem do maquinal, em Bakhtin (1968) o riso é descrito enquanto acto de festividade, através do qual o indivíduo exprime vivamente (e não maquinalmente) uma pertença. Baseando-se na obra publicada pelo autor renascentista François Rabelais, a análise de Mikhail Bakhtin associa o riso a um acto de revelação individual e social que, pela sua própria existência, atenta contra as mais básicas fundações da moral e da autoridade vigentes durante a era medieval.

O objectivo deste artigo é relacionar a visão bakhtiniana do riso com os princípios basilares da nova gestão dos recursos humanos, paradigma organizacional que elege tanto o riso, como outros traços humanos como elementos fundamentais na administração dos trabalhadores e no relacionamento da empresa com o cliente. Não se trata aqui de assumir a vitória da primeira sobre a segunda, mas sim de descrever uma dialéctica em constante desenvolvimento. E esta passa por considerarmos o riso não só como algo predeterminado, fruto de uma tentativa de invasão do domínio da vida por parte do domínio económico, mas como um excesso que, ao não ser recuperado e inserido numa cultura de empresa, a afronta.

1. 0 riso e a ordem do grotesco

3 "De todas as criaturas vivas apenas o Homem é dotado de riso", afirmou Aristóteles. A asserção do filósofo grego não somente remete o riso para uma esfera biológica, como se o riso constituísse a manifestação do lado mais animal da pessoa, como o considera derivado de um privilégio espiritual. 
4 Em Bakhtin (1968), com base na obra de Rabelais, o poder do riso é analisado no âmbito da cultura medieval na qual se insere, nomeadamente nas festas populares e nos mercados. Nestes espaços, o riso, embora partisse de uma postura corporal, depressa adquiria um cariz social simultaneamente rejuvenescente e provocador.

5 Antes de mais, o riso era uma expressão do realismo grotesco, termo herdeiro do italiano grotta, designação dos ornamentos que decoravam os banhos de Tito e que retratavam, de forma escandalosamente directa e harmoniosa, as formas humanas, vegetais e animais. $\mathrm{O}$ grotesco enfatiza o que é material, natural e incoerente e não o que é ideal e abstracto, sendo o corpo apresentado "não de uma forma privada, egotista, separado das outras esferas da vida, mas como algo universal, que representa todas as pessoas (...), corpo colectivo ancestral de todas as pessoas" (Bakhtin, 1968: 18). A coexistência, assinalável na relação entre pessoas e meio, surge como uma qualidade inerente a uma ordem natural que enforma todas as etapas da vida, inclusive a derradeira, para lá da qual aparentemente nada se parece encontrar. Porém, a negação e a destruição (a morte do velho) são incluídas como uma fase essencial, inseparável da afi rmação, do nascimento de algo novo e melhor (Bakhtin, 1968: 62).

6 O retrato de uma velha grávida ou a expressão "Que Deus urine nesta terra" denunciam a crença num poder rejuvenescedor da vida (e da morte), mesmo das suas componentes mais escatológicas, então encaradas não como desperdício, mas como meio de fertilização e de criação. Era com o objectivo de celebrar esta congruência, assinalável na mudança das estações do ano, da lua e do sol, dos períodos de cultivo agrícola, e de se exaltar "as esperanças das pessoas em relação a um futuro melhor, de uma ordem económica e social mais justa, de uma nova verdade" (Bakhtin, 1968: 81) que se organizavam carnavais e festas populares.

7 Corporizado pelas camadas sociais menos privilegiadas - estudantes, membros das corporações profissionais, bases das hierarquias religiosas, entre outros --, o riso assumiase como um elemento definidor de uma realidade festiva. 0 seu papel era o de revelador da verdade - do grotesco, do corpo, do material - e, consequentemente, de arma de arremesso contra os mais elementares princípios da ordem medieval, em particular do poder eclesiástico. Por um lado, o próprio ambiente de festa em que o riso surge representa a rejeição do modo de organização socialmente prevalecente, verificando-se, durante o período de festa, uma "suspensão temporária de todas as distinções hierárquicas e barreiras entre os homens, bem como de certas normas e proibições usuais" (Bakhtin, 1968: 15). Por outro, o riso, apesar de tomar como objecto tudo e todos (até o próprio), não discriminando ninguém, atribuía uma especial relevância às autoridades religiosas. Afi nal, estas representavam tudo aquilo que atentava contra a lógica da festa: o sagrado contra o profano, o espírito contra o corpo, a penitência contra o riso, o medo contra a alegria. 0 riso que aponta, acusa, denuncia e ataca não é mais do que o fruto de uma força colectiva que liberta as pessoas "não apenas de uma censura externa, mas mais do que tudo, do grande censor em nós" (Bakhtin, 1968: 94).

Na Festa dos Loucos, celebrada em Espanha, França, Alemanha, Inglaterra e Escócia, uma "missa" era celebrada ao som de urros a imitar o zurrar dos burros; por sua vez, o cheiro intenso do incenso era substituído pelo odor ainda mais intenso de excrementos. É importante referir, contudo, que frequentemente é a própria hierarquia religiosa que permite a introdução deste género de práticas nos cerimoniais oficiais: na Páscoa, a título de exemplo, a igreja tornava-se num espaço onde o riso e as piadas não só eram 
admitidos, como se dotavam de uma carga simbólica, representando a alegria sentida na ressurreição de Cristo.

Quer um cenário como este, marcado pela fusão de realidades profundamente antagónicas, quer a política de tolerância das autoridades medievais reflectem questões de governação e de reconhecimento de uma inevitabilidade: a de que as pessoas possuem uma natureza animal, da qual não conseguem escapar. Como se podia ler numa carta circular editada pela Escola de Teologia de Paris, datada de 1444:

as pipas de vinho rebentam se de vez em quando não forem abertas, para que se possam encher de ar. Todos nós, homens, somos pipas mal juntas, cujo vinho da sabedoria rebentaria caso permanecesse em constante fermentação con $\neg$ sagrada e temente a Deus. Devemos dar-lhes ar para que não se estraguem. É por isso que permitimos festa em determinados dias, para que possamos mais tarde regressar com um maior zelo ao serviço a Deus. (Bakhtin, 1968: 75)

Este factor, aliado a uma condescendência por parte do sistema feudal, permitia momentos de libertação temporária, de suspensão do tempo religioso, de afirmação e celebração do diálogo, da horizontalidade e da comunidade. Contudo, constituindo uma efemeridade, muitas vezes integrada em rituais religiosos (ou paralela aos mesmos), não acabará a festa por perpetuar a lógica vigente, assumindo a função de refrear os ânimos, aquecendo-os, ou, tal como apontado pelos teólogos parisienses, de deixar entrar ar nas pipas para que não estoirem? Até que ponto é que o conteúdo destes acontecimentos, ao tornar-se numa particularidade de uma ordem dominante, não perde "a sua margem crítica e punção criativa, ficando paralisada, como um pássaro na gaiola, um tigre sem garras ou, recorrendo à expressão de Bakhtin, 'um peixe no aquário"' (Yol-Jung, 1998: 104)? Será a excepção a renúncia ou a confi rmação da regra?

11 Não obstante a sua natureza momentânea, a vivência e a convivialidade experimentadas nas festas populares acabavam por ter expressão noutras dimensões da vida medieval, sendo difícil separar o que é festivo do que não é festivo. Deste ponto de vista, embora Bakhtin reconheça na festa um acontecimento cuja essência nega o quotidiano, não o analisa isolado desse mesmo quotidiano, mas sim numa base de mútua dependência: a festa determina e é determinada pelo meio que a envolve, com o qual mantém uma profunda relação de antagonismo.

12 As relações sociais desenvolvidas nos mercados medievais são ilustradoras deste facto. Estes auferem de uma "certa extraterritorialidade num mundo de ordem oficial e ideológica", constatando-se a criação de um "peculiar segundo mundo no seio da ordem medieval" (Bakhtin, 1968: 153 e 154). Um dos principais traços distintivos deste "segundo mundo" é a construção de uma prática discursiva que, a par de outras práticas sociais não discursivas - o riso por exemplo -, se realiza de uma forma aberta, barulhenta e sem preconceitos. No mercado, aquele que fala para a multidão

não se apresenta a si próprio como seu oponente, nem ensina, acusa ou intiᄀmida.

Ele ri com ela (...). Existe um discurso absolutamente alegre e destemido, livre e honesto, que ecoa na praça festiva à margem de todas as proibições, limi-tações e convenções verbais. (Bakhtin, 1968: 167)

Dos pregões aos anúncios, das piadas às blasfémias, das maldições aos perjúrios, encontramos no mercado toda uma linguagem que lhe é própria e que, como acontece nas festas, só pela sua mera existência materializa um ataque contra "os princípios fundacionais do pensamento medieval, os métodos de determinação da verdade e convicção, inseparáveis do medo, da violência, de uma intolerância e seriedade taciturna e tacanha" (Bakhtin, 1968: 167, 168). No entanto, ao invés de uma contestação directa e 
reivindicativa enquanto tal, a praxis carnavalesca inclui-se naquilo que James Scott designou de registos ocultos, actos de resistência que não assumem abertamente uma postura, mas sim uma "política do disfarce e de anonimato" baseada no "duplo sentido ou na salvaguarda da identidade dos actores" (Scott, 1990: 19). No entanto, tais práticas não deixam de se orientar por um objectivo político (a oposição a uma pessoa e/ou instituição ou a defesa de um conjunto de princípios), ou mesmo por uma estratégia (Scott, 1990: 136). Ao descrever o Carnaval, Scott realça a possibilidade de, durante o acontecimento, o interdito se tornar norma, direccionando-se contra "figuras do poder dominante, mais que não seja pelo facto de tais figuras serem, por virtude do seu poder, virtualmente imunes a uma crítica aberta" (Scott, 1990: 174).

Para os sem-poder, a festa e o mercado eram, em suma, esferas de concretização de um infrapoder e, consequentemente, de uma infrapolítica, isto é, de um poder clandestino e não reconhecível exercido pelos que são, por condição, subjugados "para lá do evidente termo do espectro" (Scott, 1990: 183), determinado pela consciência das relações de dominação em que se encontra circunscrito e que, ainda que sob disfarce, tendem a "deixar algumas pistas durante a sua passagem" (Scott, 1990: 200).

Talvez por não se revelar capaz de esconder o que deveria oculto estar, ou pela dimensão dos traços que se deixam durante a passagem - maiores do que suposto -, as festas populares começaram a ser alvo de intolerância e repressão por parte das autoridades medievais. O seguinte episódio, descrito por James Scott em Hidden Transcripts, é elucidativo das eventuais consequências da revelação pública, ou de um mero alastrar de um registo oculto:

Contra uma experiência de tropas saqueadoras, peste e impostos extorsio $\neg$ nários, Hans Keil recebe um sinal de Deus e uma mensagem de um anjo. As suas vinhas sangravam à medida que eram podadas. $\mathrm{O}$ anjo desceu à terra para prometer uma punição colectiva pela ruindade humana. Os pecados que o anjo prometeu punir eram, em particular, as esmagadoras exacções de grão e trabalho por parte da nobreza, os dízimos do alto clero e o fracasso das avarentas, desavergonhadas e vaidosas elites no cumprimento das ordens de Deus. (...) o perigo da mensagem de Deus, exposta por Hans Keil, era o facto do campesinato a interpretar como um sinal que os autorizava a resistir ao pagamento de impostos. À medida que as histórias do milagre circulavam na região, através de jornais impressos e versos populares sobre os feitos de Hans Keil, as autoridades previram o perigo de uma revolta generalizada contra os impostos. As medidas que tomaram com vista a prevenir a difusão dos relatos populares são instrutivas. Os jornais alusivos ao milagre foram apreendidos, e os tipógrafos, trovadores e trabalhadores itinerantes que os espalhavam foram detidos. Qualquer um apanhado a discutir o assunto, especialmente em mercados e estalagens, devia ser detido e interrogado". (Scott, 1990: 126)

16 A própria obra de François Rabelais ilustra este avançar dos acontecimentos: o seu conteúdo, outrora retrato de um mundo popular, passa a ser objecto de comentário e discussão entre uma elite de eruditos, que se arroga do "mesmo direito que antes era concedido quase furtivamente à canalha plebeia, salvo que o exerce com graça, e não com violência" (Eco, 2007: 149).

17 As considerações de Thomas Hobbes relativamente ao riso refl ectem, de certa maneira, uma espécie de diagnóstico dos novos modos de apresentação e contenção do indivíduo na sociedade. Insuspeito de uma adesão radical à doutrina eclesiástica ${ }^{1}, \mathrm{o}$ autor relaciona o riso com manifestações de superioridade em relação ao outro, inferiorizado. Neste sentido, "a disposição para rir (...) não é mais nada senão a disposição para insistir na 
nossa própria superioridade. Contudo, tal agressão (...) é uma evidente ameaça para a paz e, consequentemente, uma afronta às leis da natureza" (Skinner, 2002: 172).

2. $O$ trabalho contra a festa

18 A contenda moral contra a festa e os maus costumes revelou-se, contudo, incapaz de suprimir o clima de ingovernabilidade das cidades pré-industriais do século XVIII, frequentemente identificado pelas revoltas das camadas sociais mais pobres - a turba contra a carestia de vida e por mudanças de natureza política e económica (Hobsbawm, 1965). A pouca cortesia com que estas aconteciam evidenciava o lento processo de governo e domesticação da sociedade, nomeadamente das suas classes mais populares.

19 O arranque da industrialização obrigava a que a esta situação fosse mitigada, de modo a que à nova máquina de produzir pudesse corresponder um produtor mecanizado. Uma vez que a prestação do trabalhador dependia do que o mesmo havia feito nos seus "tempos livres", tornou-se vital a extensão da "sirene e do relógio da fábrica" (Thompson, 1981: 444) às demais esferas da vida da pessoa.

20 A intervenção da igreja metodista britânica representou um papel determinante na persecução deste objectivo, funcionando como sua alavanca moral: a defesa de leis contra o adultério, o consumo de bebidas alcoólicas ou o canto de trovas profanas, bem como a educação das crianças, seres de "corrupta natureza e disposições maléficas" (Thompson, 1981: 444)², correspondiam a algumas das suas sacrossantas metas.

21 De facto, o quotidiano popular continuava a ser preenchido por ocasionais dias de festa e festivais, onde as mais variadas formas de diversão pecaminosa - da gula, ao jogo, passando pelo combate - eram praticadas. A violação de pressupostos morais e religiosos era tal, que as próprias autoridades atribuíam a este tipo de evento um profundo cariz subversivo, classificando-o como "o rendez vous para a insubordinação e o sinal para a insurreição" (Thompson, 1981: 445).

Ao longo dos séculos XVIII, XIX e até XX, o comportamento do operário fora do trabalho prendeu as atenções das autoridades económicas, políticas e sociais, que desenvolveram esforços com vista à reprodução social do modelo fabril. A relação directa entre a expansão do trabalho industrial e as práticas do operariado é, segundo Gramsci (1968), expressa nas preocupações que o fordismo nutriu em relação ao estado de saúde da sua mão-de-obra. A moralização de uma sexualidade monogâmica ou a política proibicionista do consumo de álcool são refl exos da luta contra a animalidade do humano, designadamente

um processo ininterrupto, muitas vezes doloroso e sangrento, de sujeição dos instintos (naturais, isto é, animalescos e primitivos) a sempre novos, complexos e rígidos hábitos e normas de ordem, exactidão e precisão, que tornem possível as formas sempre mais complexas de vida colectiva, que são a consequência necessária do desenvolvimento do capitalismo. (Gramsci, 1968: 393)

23 A tentativa de cerco ao estilo de vida operário nunca se demonstrou, porém, absolutamente eficaz. Ao descrever os hábitos culturais da classe operária britânica, Richard Hoggart deparou-se, não com o desespero e a comiseração, mas sim com uma "boa disposição", associada a um "inconformismo realista" e à necessidade de "levar as coisas com alegria" (Hoggart 1973: 159 e 160). O investimento em bens alimentares, em detrimento da casa, a ausência de planeamento económico a nível familiar, a valorização dos encontros entre amigos e das festas, a recusa da privação, são traços de uma "espécie de hedonismo, que considera a vida muito aceitável, desde que se consigam evitar as 
grandes preocupações (as dívidas, a bebida, a doença), e enquanto seja possível 'ter alguns prazeres"' (Hoggart, 1973:163).

O elogio da vida, da festa e do prazer é visível na imagem do herói da classe trabalhadora, mais próxima do popular retratado nos quadros de Brueghel do que da figura do trabalhador sério, esbelto, musculado e disciplinado, representado nos cartazes de propaganda política, tanto à esquerda, como à direita, correspondendo ao perfil do:

homem de meia-idade, grande e gordo, de cara redonda, amigo da pinga, das caricaturas e dos postais humorísticos. É ele o verdadeiro herói das classes proletárias, o herói cómico, e não o herói romântico. Não é um bonito rapaz, mas um homem de mais de quarenta anos, que teve na vida momentos difíceis, mas que soube superá-los. (Hoggart, op. cit.: 164)

3. 0 riso no trabalho

Procura-se [Editor de Vídeo + Pós-Produção em AE Freelancer]! ${ }^{3}$

Procuramos colaboração de um editor de vídeo para integrar um projecto televisivo

no-cost a estrear no Porto Canal, inícios de 2010.

PERFIL DO CANDIDATO:

- Bom gosto e excelente cultura visual;

- Cumprimento de deadlines;

- Vontade de aprender e trabalhar com profissionais na área da televisão e do entretenimento;

- Experiência com Premiere e After Effects;

- Rapidez e talento em edição vídeo;

- Dá-se preferência a residentes no Grande Porto;

OFERECEMOS

- Oportunidade de desenvolvimento pessoal e profi ssional;

- Cimentar conhecimentos e portfolio;

- Cafés e boa disposição! :)

O trabalho não será remunerado e deverá ser feito em regime de teletraba-lho, com realização de algumas reuniões semanais.

Contamos contigo!

O anúncio de emprego acima publicado poderá ser objecto de análise a partir de várias das suas prerrogativas, desde o recurso a termos técnicos ao tipo de qualidades pessoais requisitadas. Contudo, o que mais nos despertou a atenção foi precisamente a relação entre a oferta de Cafés e boa disposição - ao qual se acrescentou um ponto de exclamação e um sorriso, bastante utilizados nas mensagens de telemóvel - e a não-remuneração do trabalho. Tanto o cariz pouco convencional destes dois elementos como a sua correspondência sequencial indiciam algumas das características-base das novas formas de se trabalhar: a crescente indefinição entre trabalho e não-trabalho, ao ponto de nos ser oferecida a possibilidade de construir relações pessoais no local de trabalho, via cafés e boa disposição; e o incremento da informalidade e precariedade das relações laborais, através das mais diversas formas - contrato a prazo, trabalho independente (ou a "recibo verde"), trabalho temporário ou o estágio não remunerado.

A nova economia pós-fordista, geradora e gerada por conhecimento, veio introduzir profundas alterações no mundo do trabalho. Uma vez que a efi cácia produtiva do pensamento, da reflexão e da comunicação depende da sua livre fluidez - não devendo estes ser alvo apenas de um minucioso controlo, mas sim de uma atitude de incentivo -, tornou-se necessária a substituição de burocracias verticais por equipas de trabalho dotadas de certos poderes (por exemplo, na definição da repartição dos deveres entre os trabalhadores, na variação dos rit-mos de trabalho ou no controlo dos resultados) ${ }^{4}$. Para que "os operários amem o seu trabalho, assimilem os objectivos da empresa e mobilizem 
as reservas de produtividade que eles normalmente guardam para si próprios" (Gorz, 1988: 85).

27 Ao exigir mais do que um esforço físico, as novas formas de produção vieram dificultar a distinção entre a pessoa e o trabalhador. Daí os departamentos das empresas responsáveis pela formação e administração da mão-de-obra adoptarem a designação de "recursos humanos". Trata-se de uma operação de biopoder (Foucault, 2007), de um trabalho a fazer sobre as pessoas, levando-as a enfatizar umas qualidades em detrimento de outras, ou mesmo a adquirir traços que são objecto de procura por parte das empresas. À pessoa que trabalha é-lhe exigida uma produção de si própria por si própria, mas não segundo si própria e não necessariamente para si própria, pois antes de mais ela constitui capital humano, um

fragmento de capital, uma fracção molecular do capital. (...), um capitalcompetência, uma "máquina-competência", que leva a cabo um "estilo de vida, um modo de vida", uma escolha moral, uma forma de relação do indivíduo consigo mesmo, com o tempo, com os seus círculos, com o futuro, com o grupo, com a família. (Lazzaratto, 2008: 33, 34)

Estamos perante uma nova economia política em que o trabalho, ao deixar de constituir capital variável para assumir a categoria de capital fixo (pois é constante a necessidade de aplicação de trabalho imaterial na empresa), deve ser reproduzido sob os auspícios do capital. Doravante,

todo o valor que, de acordo com a teoria da acumulação, não era colocado no interior do regime capitalista imediato (como o poder social de reprodução, o excedente produtivo da cooperação, a "pequena circulação", as novas necessidades e desejos produzidos pelas lutas) é agora imediatamente recuperado e transportado para o interior do regime (global) de controlo capitalista. (Negri, 1996:4)

O cruzamento entre vida, capital e trabalho leva a que o "lugar das emoções" já não mais corresponda apenas ao espaço ocupado entre familiares, amigos ou amantes, mas igualmente entre colegas, superiores hierárquicos ou clientes.

A consideração da esfera emocional no conjunto das estratégias de gestão dos recursos humanos é patente, por um lado, nas relações sociais no seio da empresa e, por outro, no contacto realizado entre trabalhador e cliente.

31 A influência emocional sobre o processo de produção já havia sido identificada durante a era industrial. Embora Max Weber tenha pugnado por uma "orientação tecnicamente racional do processo de trabalho" (Weber, 2004: 89), ao ver perigo nas "obstruções tecnicamente irracionais e irracionalidades económicas" (Weber, 1990: 90), não defende na sua teoria uma incompatibilidade com a inclusão das emoções no domínio produtivo, desde que tais fossem sujeitas a uma administração racional. A sua sociologia não incompatibiliza o racional e o irracional, preconizando um olhar que observa a sociedade a partir dos seus diversos componentes e da sua inter-relação, da "exploração de uma dialéctica" (Albrow, 2004: 104). Ao associar o desenvolvimento do capitalismo à força de uma ética que encarava o negócio enquanto virtude e a profi ssão enquanto dever, Weber destaca a função que o sentimento (neste caso, o de dever cumprido) pode desempenhar na actividade da empresa, ao argumentar:

Coisa diferente (...) só costuma acontecer com moças de educação espe-cificamente religiosa, nomeadamente de origem pietista. (...) A capacidade de concentração mental bem como a atitude absolutamente central de sentir-se no "dever de trabalhar" encontram-se aqui associadas com particular frequência a um rigoroso espírito de poupança que calcula o ganho e o seu montante geral, a um severo 
domínio de si e uma sobriedade que elevam de maneira excepcional a produtividade. Para essa concepção de trabalho como fim em si mesmo, como "vocação numa profissão", o solo aqui é dos mais férteis, e das mais amplas as oportunidades de superar a rotina tradicionalista em consequência da educação religiosa. (Weber, 2004: 55 e 56)

A racionalidade do empresário capitalista no processo de recrutamento de trabalhadores parece inscrever-se numa lógica, não de eliminação do pendor irracional da pessoa humana, mas sim na sua selecção de acordo com o eventual contributo para a consecução de fins mensuráveis, sujeitos a um cálculo científico.

A passagem do taylorismo ao toyotismo - de um trabalho que se executava isoladamente num qualquer ponto da linha de montagem a um conjunto de funções que passam a ser discutidas em equipa - veio tornar a afectividade num aspecto fulcral da performance organizacional. A já mencionada dependência crónica das empresas em relação às capacidades dos trabalhadores obrigou a que estas tivessem que se tornar em "comunidades práticas", imbuídas de um conjunto de valores, princípios e atitudes "subjacentes à visão, missão e objectivos de uma organização empresarial" (Holmes e Marra, 2002: 1684). Facilita-se, assim, a adesão dos trabalhadores a uma normatividade específi ca e ao cumprimento de um dever que, tendo como objecto uma "comunidade", uma "família", adquire uma carga moral. A própria ideia de "missão empresarial" remete para um processo de conversão de trabalhadores em convertidos, seguidores e discípulos das "sagradas" metas da empresa.

Parte desta cultura, o riso e o humor contribuem para a construção e perpetuação de um ambiente de harmonia e coesão, "de energia, de bom-humor, de agradável interacção, com todas as características do 'todos juntos, agora!"' (Holmes e Marra 2002: 1689). Estes factores são tanto mais importantes quanto maior for a exigência de esforço e de cooperação entre colegas, devendo assim integrar o reportório de qualidades do coordenador de equipa, que deve ser:

o homem da conexão confia nas suas aptidões comunicativas, no seu temperamento familiar, na sua mente curiosa e aberta. Mas ele também sabe dar-se, estar lá quando é preciso, explorar a sua presença nas relações pessoais, nos encontros frente a frente: ele está sempre disponível, calmo, confiante sem ser arrogante, íntimo mas sem ultrapassar os limites, prestável, com mais para ofere $\neg$ cer do que espera vir a receber. (Boltanski e Chiappello, 2007: 114)

Podemos mesmo afirmar que o recurso ao humor se assume como fundamental na realização de dois pressupostos essenciais de uma nova forma de se gerir pessoas. Em primeiro lugar, preocupar-se menos em obrigar e mais em incentivar (uma imposição das qualidades humanas que alimentam a máquina produtiva, desenvolvidas a partir de uma atitude de solicitação e não "tiradas a ferros"), podendo a piada (nunca o gozo), ao substituir a repreensão, contribuir para a autoconfi ança e mobilização de um trabalhador com um menor nível de produtividade (Holmes e Marra 2002: 1699). Em segundo lugar, o poder rir-se à vontade - perante o superior hierárquico e com o superior hierárquico cria um ambiente de intimidade, incrementa o envolvimento e a criatividade do trabalhador (Rodrigues e Collinson, 1995) e ofusca a figura da autoridade, sem que, contudo, esta deixe de ser exercida. Este clima, consubstanciado pela ideia de que trabalhar é antes de mais participar no cumprimento de uma missão (não apenas de um contrato), poderá difi cultar a eclosão de confl itos entre trabalhadores e chefias: porque é difícil exigir, reclamar, negar, atacar uma pessoa com a qual se privou na festa de Natal da empresa ou no jantar do grupo de trabalho. Em suma, a formação de uma cultura de empresa como 
base de relações de proximidade, mesmo de intimidade, entre subordinantes e subordinados, parece legitimar todo um conjunto de situações marcadas pela precariedade e instabilidade dos vínculos contratuais. Deste ponto de vista, e não descurando outros factores igualmente relevantes, tomar café num ambiente de boadisposição é inseparável de se exercer um trabalho sem se ser remunerado.

Para além de contribuir para a estabilidade interna das empresas, a expressão de emoções (ou pelo menos a demonstração de tal) desempenha um papel importante na relação entre cliente e trabalhador. Num estudo sobre a perfor-mance das hospedeiras de bordo, Arlie Hoschild constatou como a entrega de "amor comercial" (Hoschild, 1993: 328) se impunha como tarefa a realizar pelas trabalhadoras. Ser-se delicada, simpática, atenta às vontades das pessoas, sorridente e, ao mesmo tempo, saber lidar de forma adequada com o nervosismo, impaciência e indelicadeza do cliente são requisitos obrigatórios do ser-se hospedeira. Numa acção de formação de pessoal descrita pela autora, as candidatas à profi ssão foram aconselhadas ao seguinte: "Meninas, quero o vosso sorriso. $O$ vosso sorriso é o vosso melhor atributo. Portanto, quero que vocês o utilizem. Sorriam. A sério, usem-no. Sorriam" (Hoschild, 1993: 329).

Ao terem que administrar as emoções das outras pessoas, as hospedeiras viam-se obrigadas a incorporar determinados tipos de postura e atitudes que obedecessem às expectativas e interesses dos clientes, ao ponto de ser difícil separar as esferas pessoal e laboral. A penetração de uma lógica comercial na "parte sagrada do ser e alma da pessoa" (Hoschild, 1993: 333) faz com que uma postura superficial se possa tornar numa forma de actuação profunda, uma espécie de devir laboral, em que a pessoa existe para o trabalho que tem ${ }^{5}$.

O dever existencial das hospedeiras de bordo não constitui uma peculiaridade desta profi ssão, nem tampouco traduz uma exigência inerente a certo tipo de empregos qualificados, posteriormente recompensada em termos de status e rendimentos. Se considerarmos o trabalho realizado nos call-centres (Venco, 2006) e nos supermercados (Cruz, 2003), deparamo-nos com a combinação de uma rígida disciplina e estandardização com a aplicação de elementos imateriais: o tom com que se fala, a fluidez do discurso, a delicadeza com que se atende uma reclamação ou o poder de sedução necessário à realização de uma venda; ou o "ter 'tacto', 'habilidade', 'diplomacia"' (Cruz, 2003: 131), conforme a "política do sorriso constante estampado no rosto" (Cruz, 2003: 130) ${ }^{6}$. Em ambos os casos, a sua missão ultrapassa em muito o número de vendas obtidas ou de pessoas atendidas, tendo em vista a fidelização do cliente. Tal meta exige processos laborais que têm como meio e fim último a criação de afectos: "um sentimento de tranquilidade, de bem-estar, de satisfação, de excitação, de paixão - até um certo sentimento de ligação ou de comunidade" (Hardt, 2003: 5).

3.10 riso enquanto oculto

O investimento das empresas no domínio das emoções é um risco embutido de fortes contradições. A descrição da seguinte conversa entre uma hospedeira de bordo e um cliente elucida-nos da falibilidade deste processo:

Num voo de 15 horas de Hong-Kong para Nova Iorque, um jovem empresário pousa a sua bebida, coloca-se para trás e aborda uma hospedeira de bordo, que puxa ao longo do corredor um carro de refeições com um peso de $50 \mathrm{~kg}$. "Ei querida", ele chama, "dá-me um sorriso". A hospedeira de noite pára o carro. Limpa a testa e olha-lhe nos olhos. "Fazemos o seguinte", diz ela. "O senhor sorri primeiro e depois 
sorrio eu, OK?". O empresário sorriu para ela. “Bom”, ela respondeu. “Agora, fi que quieto e aguente durante 15 horas. (Hoschild, 1993: 328) surgir como meios de dessacralização da cultura de empresa e de crítica da autoridade. Num estudo sobre o comportamento de operadores de call-centres, Taylor e Bain (2003) identifi caram uma metodologia de contestação que, entre as diversas tácticas utilizadas da sabotagem de material ao espalhar de boatos -, recorria a piadas. Normalmente direccionado a pessoas, embora igualmente versasse sobre outros aspectos do quotidiano empresarial, o poder da piada assenta, por um lado, no facto de proporcionar momentos de relaxamento (nomeadamente em trabalhos repetitivos e fatigantes) e, por outro, no seu efeito centrífugo, manifesto num riso que, ao tornar-se generalizado, coloca o seu objecto sobre um sentenciar colectivo, muitas vezes expresso de forma jocosa e pouco dignifi cante.

43 Num jantar de Natal de uma das companhias analisadas pelos autores, um trabalhador que havia saído com a filha de um director executivo respondia de forma irónica e burlesca a perguntas relativas aos pormenores mais íntimos do encontro. Perfilhada de risos e comentários jocosos, a conversa foi sentenciada por um dos colegas - "É a primeira vez que um Martin [o apelido do director executivo/da sua filha] é fodido por alguém daqui", uma observação que "enfatiza a

distância entre empregados e administração executiva, e demonstra uma apreciação das realidades do poder e da autoridade" (Taylor e Bain, 2003: 1494). Numa outra ocasião, durante o trabalho, um dos operadores fez questão de avaliar a indumentária do coordenador responsável, presente no momento - "Não acre-dito que este homem ganha $£ 20000$ ao ano: já viram os seus sapatos?" (Taylor e Bain, 2003: 1501). Um comentário que submete a autoridade ao ridículo - neste caso, reduzindo o superior hierárquico a um indivíduo que se veste mal. No local de trabalho, era igualmente comum a troca de banda desenhada, poemas, imagens, pequenas histórias e forwards quer sobre pessoas, acontecimentos e características exclusivas da empresa, quer de cariz mais geral, referentes à questão salarial, aos ritmos de trabalho ou a políticas de gestão de recursos humanos.

Tal como o folião da festa popular retratado por Rabelais, o trabalhador do call-centre utiliza o humor enquanto registo escondido (Scott, 1990), forma de crítica subliminar que, através de apontamentos indirectos e sem qualquer conteúdo político evidente (a 
revelação do encontro com a filha do director executivo ou a avaliação estética dos sapatos do coordenador), ataca e desgasta a autoridade. É possível igualmente estabelecer paralelismos no que respeita à contextualização espacial do registo escondido. Durante a era medieval, a comunicação sem barreiras, essencial para que a crítica se pudesse partilhar entre as pessoas, exigia "um refúgio parcial das humilhações da dominação" (Scott, 1990: 114), encontrado na feira e no mercado medievais. Actualmente, as últimas novidades em termos de tecnologia de vigilância, aliadas à desconcentração das grandes unidades produtivas, vêm dificultar a organização de santuários dentro das empresas. No entanto, não o tornaram impossível.

A casa de banho, a sala de fumo e/ou de convívio, os refeitórios ou os corredores de acesso (Cruz, 2004) são exemplos do que Goffman designou de "regiões de traseira" ou "bastidores", onde "o actor poderá descontrair-se, pôr de lado a sua fachada, interromper a encenação e abandonar a personagem que no respectivo quadro desempenha" (Goffman 1993: 135 e 136): falar alto, desapertar o uniforme, queixar-se, dizer mal, contar anedotas, rir. Ao facilita-rem a livre partilha de expectativas, frustrações, desejos, opiniões, estes espaços acabam por constituir potenciais locais de subversão, indiciando "uma distinta subcultura organizacional, em conflito directo com os valores e prioridades da gestão" (Taylor e Bain, op. cit: 1495).

Conclusão

47 Ao produzir e ser produzido não por um só, mas por uma multiplicidade de sujeitos, o riso surge como um acontecimento comum ${ }^{8}$, "é o riso de todas as pessoas (...), é universal no seu âmbito; é dirigido a todos e mais algum, inclusivamente os participantes no Carnaval" (Bakhtin, 1968: 12). Partindo de uma performance individual, o riso estende-se a outros corpos e abarca toda a realidade - do mais "simplório" camponês à mais alta autoridade religiosa - sem quaisquer complexos discriminatórios: toda a pessoa é um potencial sujeito e objecto de escárnio. Consubstanciado por outros elementos, igualmente parte dessa obra feita em comum, o riso expõe-se de distintas maneiras, é motivado por diversos factores, "exprime a diferença de desejos, de reivindicações subjectivas, que nada tem a ver com a unidade de um processo de comando" (Negri, 2007: 67).

Actualmente, os novos modos de trabalhar, crescentemente indistintos dos novos modos de viver, vieram alterar as formas de encarar o riso. De elemento transgressor, o riso passa a ser encarado como factor de consolidação organizacional, resultado da elevação dos dons e capacidades dos trabalhadores aos meios de produção. Reconhece-se assim que "o valor é formado na relação de afecto, que o afecto tem as suas qualidades produtivas fundamentais", e reconhece-se também a concomitante necessidade de "o controlar (e mistifi car a sua natureza), limitando o seu poder" (Negri, 1996: 8). Porém, a tarefa a que se propõe a actualização do taylorismo, ao tomar como objecto aquilo que há de mais íntimo e de imprevisível na pessoa, é, no mínimo, quimérica. Ainda mais quando se faz acompanhar de práticas laborais que contradizem um pretenso "humanismo empresarial". Tal como no passado, o riso, conforme evidenciado pelos comentários e piadas proferidos pelos trabalhadores dos call-centres, tende a surgir como "registo escondido", aproveitando-se estrategicamente quer do clima de descontracção e de informalidade (dos cafés e da boa disposição), quer do seu duplo sentido, pela capacidade de - indirectamente, muitas vezes de forma ambígua - causar um mal-estar na pessoa e/ou instituição visada. Por ser parte, nas palavras de James Scott, "de um discurso não hegemónico, de contraponto, dissidente, subversivo" (Scott, 1990: 125), o riso indicia essa mesma "autovalorização que o capital não consegue inteiramente reabsorver" (Negri, 
2007: 43), ou seja, uma parte da vida que, ao recusar ser penetrada pela lógica da mercadoria, antagoniza essa mesma lógica.

\section{BIBLIOGRAFIA}

ALBROW, Martin (2004), Do Organizations Have Feelings?, Londres: Routledge.

BAKHTIN, Mikhail (1968), Rabelais and His World, Cambridge: MIT Press.

BAKHTIN, Mikhail (1997), “The Epic and the Novel”. In M. Bakhtin, The Dialogical Imagination, Austin: University of Texas Press, pp. 3-40.

BAUDELAIRE, Charles (2001), Da Essência do Riso, Almada: Íman.

BOLTANSKY, Luc e CHIAPELLO, Eve (2007), The New Spirit of Capitalism, Londres, Verso.

BOLTON, Sharon e BOYD, Carol (2003), “Trolley Dolly or Skilled Emotion Manager? Moving on from Hoschild`s Managed Heart”. In Work, Employment \& Society, Vol. 17 (2), pp. 289-308.

CRUZ, Sofia Alexandre (2003), Entre a Casa e a Caixa: Retrato de trabalhadores na grande distribuição, Porto: Afrontamento.

EMERSON, Caryl (1997), The First Hundred Years of Mikhail Bakhtin, Princeton: Princeton University. ECO, Umberto (2007), A História do Feio, Miraflores; Difel.

ELIAS, Norbert (1998), Norbert Elias, on Civilization, Power and Knowledge: Selected writings, Chicago: University of Chicago Press.

FOUCAULT, Michel (2007), Security, Territory, Population, Hampshire: Palgrave-Macmillan.

GORZ, André (1988), Métamorphoses du travail quête du sens : critique de la raison économique, Paris, Galilée.

GOFFMAN, Erving (1993), A Apresentação do Eu na Vida de Todos os Dias, Lisboa, Relógio d’Água.

GRAMSCI, Antonio (1968), Maquiavel: A política e o Estado moderno, Rio de Janeiro, Civilização Brasileira.

HARDT, Michael (2003), “Affective Labour”. Disponível em http://www.generation-online.org/p/ fp_affectivelabour.htm. Consultado em 2009-04-16.

HITCHCOCK, Peter (1998), “The grotesque of the Body Electric”. In M. M., Bell, Bakhtin and the Human Sciences: No last words, Londres: Sage Publications, pp.78-94.

HOBBES, Thomas (1999), O Leviatã, Lisboa: Imprensa Nacional-Casa da Moeda.

HOBSBAWM, Eric (1965), Primitive Rebels, Nova Iorque: Norton Library.

HOGGART, Richard (1973), As Utilizações da Cultura: Aspectos da vida da classe trabalhadora, Vol. I, Lisboa, Editorial Presença.

HOLMES, Janet e MARRA, Meredith (2002), «Having a Laugh at Work: How Humour Contributes to Workplace Culture». In Journal of Pragmatics, no34, pp. 1683-1710. 
HOSCHILD, Allie (1993), “The Managed Heart”. In P. Rothenberg, A. Jaggar, Feminist Frameworks, Boston: McGraw-Hill, pp. 328-334.

LAZZARATO, Maurizio (2008), Le Gouvernment des inégalités, Paris, Éditions Amsterdam.

NEGRI, Antonio (2007), The Porcelain Workshop, Los Angeles: Semiotexte.

NEGRI, Antonio (1996), “Value and Affect”. Disponível em http://www.generation-online.org/t/ valueaffect.htm. Consultada em 2009-05-05.

RODRIGUES, Susana e COLLINSON, David (1995), “'Having Fun': Humour as Resistance in Brazil”. In Organization Studies, nº16/5, pp. 739-768.

SCOTT, James (1990), Domination and the Arts of Resistance: Hidden transcripts, New Haven: Yale University Press.

SILVA, Manuel Carlos (1998), Resistir e Adaptar-se. Constrangimentos e estratégias camponesas no Noroeste de Portugal, Porto: Afrontamento.

SKINNER, Quentin (2002), Visions of Politics: Hobbes and Civil Science, Vol. III, Cambridge: Cambridge University Press.

TAYLOR, Philip et BAIN, Peter (2003), “'Subterranean Homesick Blues': Humour as Subversion in Two Call Centres». In Organization Studies, n²4 (9), pp. 1487-1509.

THOMPSON, E.P (1991), The Making of the English Working Class, Londres, Penguin Books.

VENCO, Selma (2006), “Centrais de atendimento: a fábrica do século XIX nos serviços do século XXI”. Revista Brasileira de Saúde Ocupacional, no31, pp. 7-18.

WEBER, Max (2004), A Ética Protestante e o Espírito do Capitalismo, São Paulo, Companhia das Letras. YOL-JUNG, Hwa (1998), “Dialogical Body Politics”. In M. M., Bell, Bakhtin and the Human Sciences: No last words, Londres: Sage Publications, pp. 95-111.

\section{NOTAS}

1. Hobbes argumenta "que os apóstolos e outros ministros do Evangelho são apenas nossos professores e não nossos comandantes, e que os seus preceitos não são leis, mas apenas salutares conselhos" (Hobbes, 1999: 383, 384). Em Portugal, na senda de Scott (1990), formas de registo (semi)oculto' e outros 'contrapontos' contestatários de camponeses ao padre e à constituição eclesiástica foram desenvolvidas por Silva (1998: $344 \mathrm{ss}$ ).

2. $O$ autor retira esta citação de um manual professoral de uma escola metodista.

3. Anúncio de emprego disponível em http://www.cargadetrabalhos.net/2009/08/05/ multimedia-edicao-de-video-freelancer. Consultada realizada em 2009-08-27.

4. É importante mencionar o contributo exercido pelo movimento das "relações humanas", iniciado por uma série de especialistas da psicologia e da sociologia da indústria que, através de experiências como a da fábrica de Hawthorne, propuseram uma série de reformas destinadas a corrigir as deficiências do ambiente fabril e a tornar o trabalho menos insalubre.

5. As políticas de recrutamento empresarial poderão facilitar este processo, na medida em que seleccionam os candidatos com base na posse das qualidades humanas exigidas pelo trabalho a realizar.

6. Sofia Alexandre Cruz, ao analisar a prática das operadoras de linha de caixa, constatou como os requisitos necessários para o trabalho a efectuar apontavam "mais para um conjunto de qualidades pessoais que a operadora deve possuir do que para qualificações e competências de carácter profi ssionalizante" (Cruz, 2003: 129 e 130). 
7. Bolton e Boyd distinguem labor emocional, em troca de um salário, de trabalho emocional, referente à gestão das emoções realizada no dia-a-dia. Em ambos, verifica-se a indiciação de um estado emocional, consoante a situação em que a pessoa se encontra inserida (Bolton e Boyd, 2003: 293).

8. Para Negri (2007), o comum é aquilo que é produzido pelas pessoas fora da esfera do capital e de qualquer lógica heterónoma. Constitui-se a partir das relações e actividades cooperativas que possuem uma existência própria e valem por si só. Deste ponto de vista, ultrapassa a categoria de privado, pois encara como impossível a emancipação do indivíduo à parte do colectivo, e de público, porque pugna pela afirmação da subjectividade, independentemente das circunstâncias.

\section{RESUMOS}

Em Bakhtin, rir constitui um acto de regozijo popular, parte de um conjunto de práticas que invertiam a moral cristã. Actualmente, rir parece integrar-se numa ordem, não de festa, mas de trabalho. Cada vez mais, trabalhar equivale a participar numa dramaturgia social, em que a pessoa se sujeita a um processo de auto-apresentação. Tanto o seu meio, como o seu fim, parecem assentar na criação de afectos, um sentimento de bem-estar e/ou de excitação, criados - entre outros meios - pelo riso. Analisando-o enquanto parte do processo de produção, pretendemos reflectir em torno da ideia de capital humano, de como os mais íntimos traços do indivíduo se tornam objecto de uma auto-produção do trabalhador, com base nos critérios exigidos pelas empresas.

In Bakhtin, laughing can be described as act of popular rejoicing, part of a set of practices that subvert the christian morality. Nowadays, laughing seems to be easily integrated in an order, not of feast, but of work. Increasingly, work implies the participation on a social dramaturgy, in which the person subjects herself to a process of self-presentation. Both its means and its ends seem to rely upon the creation of affective elements, a feeling of well-being and/ or enthusiasm, produced, among other means, by laughter. Analyzing it as part of the production process, we intend to reflect upon the idea of human capital, that is, how the most intimate features of the individual become object of the worker's self-production, based upon criteria demanded by companies.

D'après Bakhtine, le rire est un acte de réjouissance populaire, qui appartient à un ensemble de pratiques qui renverse la morale chrétienne. Actuellement, le rire semble s'intégrer à un ordre, non pas de célébration, mais de travail. Travailler équivaut de plus en plus à participer à un drame social, dans lequel l'individu est soumis à un processus d'auto-présentation. Aussi bien les fi ns comme les moyens utilisés paraissent s'appuyer sur la création d'attachements, d'un sentiment de bien-être et /ou d'excitation, créés - entre autres - par le rire. En analysant le processus de production, l'objectif est de réfl échir sur le concept de capital humain, d'expliquer comment les caractéristiques les plus intimes de l'individu deviennent sujet d'une autoproduction, sur la base des critères requis par les entreprises. 
ÍNDICE

Mots-clés: rire, fête, transcription cachés, ressources humaines, travail immatériel, excédent Palavras-chave: riso, festa, registo escondido, recursos humanos, trabalho imaterial, excesso Keywords: laughing, feast, hidden transcript, human resources, immaterial labour, excess

\section{AUTOR}

JOSÉ NUNO MATOS

FDD-DS

as@mmnsc.ccm 